\title{
Significance of survivin expression: Prognostic value and survival in stage III non-small cell lung cancer
}

\author{
MENG WANG, BAO-GANG LIU, ZHAO-YANG YANG, XUAN HONG and GONG-YAN CHEN
}

Department of Respiratory Medicine, The Third Affiliated Hospital of Harbin Medical University, Harbin 150086, P.R. China

Received January 5, 2012; Accepted February 13, 2012

DOI: $10.3892 /$ etm.2012.512

\begin{abstract}
This study was designed to determine the levels of survivin expression and identify its clinical significance as a prognostic factor for stage III non-small cell lung cancer (NSCLC). A total of 210 cases of stage III NSCLC were collected and the expression levels of survivin and vascular endothelial growth factor A (VEGF-A) in tumor tissues were investigated using immunohistochemistry (IHC). The medical records of the patients were reviewed to determine the association with clinical course. Of the 210 NSCLC tissues, $112(53.3 \%)$ cases demonstrated positive expression of survivin protein. Coexpression of survivin and VEGF-A was identified. The 5-year survival rate of patients with positive survivin expression was significantly lower compared with the survivin-negative cancer patients $(\mathrm{P}<0.05)$. The expression of survivin in NSCLC correlated with tumor size. Survivin and VEGF-A were independent prognostic factors of stage III NSCLC. Survivin protein is a valuable marker of prognosis in stage III NSCLC patients.
\end{abstract}

\section{Introduction}

Despite its declining incidence, non-small cell lung cancer remains the most common type of malignancy in Northern China. The estimated overall 5-year survival rate is only $16 \%$ (1). The development of new treatment modalities, diagnostic technologies and preventive approaches requires an improved understanding of the molecular mechanisms of lung cancer. Therefore, the study of molecular markers to identify risk factors associated with the prognosis of NSCLC and to develop a more aggressive treatment is required.

Survivin, the smallest member of the inhibitor of apoptosis (IAP) gene family (2), is a 142-amino-acid, 16.5-kDa protein encoded by a single-copy gene located on the human

Correspondence to: Dr Gong-Yan Chen, Department of Respiratory Medicine, The Third Affiliated Hospital of Harbin Medical University, 150 Haping Road, Nangang, Harbin 150086, Heilongjiang, P.R. China

E-mail: chengongyan2012@yahoo.cn

Key words: survivin, VEGF-A, immunohistochemistry, prognostic marker chromosome 17q25. Survivin has been demonstrated to be involved in the regulation of cell proliferation, apoptosis and angiogenesis in cancer $(3,4)$. Increased survivin expression has been observed in a variety of human neoplasms, including colorectal, breast and rectal cancer, ovarian carcinoma and lymphoma (3,5-7). Multiple pathways of transcription and post-transcription control the expression of survivin, particularly in tumor cells. Survivin is one of the relatively few genes that is actively repressed by wild-type p53 $(8,9)$. Certain developmental gene expression pathways, including Notch, characterize the survivin gene for differential expression in transformed cells, which is related to tumorigenesis (10). In addition, insulin-like growth factor I/mTOR signaling has been reported to upregulate survivin through rapid changes in mRNA translation (11). Previous studies have reported various rates of expression, but little is known about the prognostic value of survivin. Therefore, in the present large case study, we performed statistical analyses to determine the significance of survivin and vascular endothelial growth factor A (VEGF-A) expression in stage III NSCLC, and the association between survivin expression and clinical outcome.

\section{Patients and methods}

Patients and samples. A total of 210 patients with pathologically proven stage III NSCLC, who underwent potentially curative tumor resection at the Third Hospital of Harbin Medical University, Harbin, China between 2002 and 2004, were included in this study. The study was approved by the Harbin Medical University Ethics Committee. The patients had received neither chemotherapy nor radiation therapy prior to surgery. The patients included 130 males and 80 females, of mean age 59.8 years (range, 35-76 years). All the specimens were confirmed as NSCLC following pathological diagnosis. Routinely processed formalin-fixed, paraffin-embedded blocks containing the principal tumors were selected. Serial sections $(4 \mu \mathrm{m})$ were prepared from the cut surface of tumor blocks at the maximum cross-section of the tumor.

Immunohistochemical(IHC) staining for survivin and VEGF-A. IHC staining for survivin and VEGF-A antigen was conducted using the standard streptavidin-peroxidase-biotin technique (SP technique) using an SP kit (Zhongshan Co., Beijing, China). Paraffin sections $(4 \mu \mathrm{m})$ were deparaffinized in xylene and then rehydated through graded alcohol. Hydrated autoclave pretreat- 
Table I. Correlation between survivin expression and clinicopathological factors.

\begin{tabular}{|c|c|c|c|c|}
\hline \multirow[b]{2}{*}{ Variables } & \multirow[b]{2}{*}{ No. of cases $(n=210)$} & \multicolumn{2}{|c|}{ Survivin expression } & \multirow[b]{2}{*}{ P-value } \\
\hline & & Positive $(n=112)$ & Negative $(n=98)$ & \\
\hline \multicolumn{5}{|l|}{ Age (years) } \\
\hline$\leq 60$ & 89 & 46 & 43 & \multirow[t]{2}{*}{0.681} \\
\hline$<60$ & 121 & 66 & 55 & \\
\hline \multicolumn{5}{|l|}{ Gender } \\
\hline Male & 130 & 69 & 61 & \multirow[t]{2}{*}{0.924} \\
\hline Female & 80 & 43 & 37 & \\
\hline \multicolumn{5}{|l|}{ Tumor size $(\mathrm{cm})$} \\
\hline$\leq 3$ & 97 & 43 & 54 & \multirow[t]{2}{*}{0.015} \\
\hline$>3$ & 113 & 69 & 44 & \\
\hline \multicolumn{5}{|l|}{ Smoker } \\
\hline Yes & 105 & 61 & 44 & \multirow[t]{2}{*}{0.167} \\
\hline No & 105 & 51 & 54 & \\
\hline \multicolumn{5}{|l|}{ Histology } \\
\hline Squamous cell carcinoma & 101 & 54 & 47 & \multirow[t]{3}{*}{0.996} \\
\hline Adenocarcinoma & 88 & 47 & 41 & \\
\hline Large-cell carcinoma & 21 & 11 & 10 & \\
\hline \multicolumn{5}{|l|}{ Lymph node metastasis } \\
\hline Yes & 108 & 55 & 53 & \multirow[t]{2}{*}{0.472} \\
\hline No & 102 & 57 & 45 & \\
\hline \multicolumn{5}{|l|}{ Pathological stage } \\
\hline G1 & 43 & 22 & 21 & \multirow[t]{3}{*}{0.776} \\
\hline G2 & 91 & 47 & 44 & \\
\hline G3 & 76 & 43 & 33 & \\
\hline
\end{tabular}

ment was carried out by boiling for $5 \mathrm{~min}$ in citrate buffer (10 mM, pH 6.0). After endogenous peroxidase was quenched in $3 \%$ hydrogen peroxide and blocked for $10 \mathrm{~min}$, the sections were incubated overnight at $4{ }^{\circ} \mathrm{C}$ with a primary polyclonal antibody (Neomarkers) at a 1:200 dilution. Biotinylated immunoglobulin and streptavidin-conjugated peroxidase were then added. Finally, 3,3'-diaminobenzidine was used for color development, and hematoxylin was used for counterstaining. Negative control slides processed without primary antibody were included for each staining. The mean percentage of positive tumor cells was determined in at least five areas at magnification x200 for survivin and VEGF-A. They were scored as follows: $(0)<5$; (1) 5-25; (2) 26-50; (3) 51-75; and (4) $>75 \%$. The intensity of immunostaining was scored as follows: $1+$, weak; $2+$, moderate; and $3+$, intense. The scores indicating the percentage of positive tumor cells and the staining intensities were multiplied together to calculate a weighted score for each case. Cases with weighted scores 0-1 were defined as negative; while the other cases were defined as positive.

Statistical analysis. All statistical analyses were performed using SPSS 13.0 software. Associations between survivin expression and clinicopathological parameters were analyzed by the $\chi^{2}$ test. The coincident expression of survivin and VEGF-A protein in the NSCLC tissues was analyzed using Spearman's correlation analysis. The survival curves were
Table II. Correlation between survivin and VEGF expression in NSCLC tissues.

\begin{tabular}{lccc}
\hline & \multicolumn{2}{c}{ VEGF expression } & \\
\cline { 2 - 3 } Survivin expression & Negative & Positive & P-value \\
\hline Negative & 62 & 36 & 0.001 \\
Positive & 45 & 67 & \\
\hline
\end{tabular}

$\mathrm{R}=0.230$. NSCLC, non-small cell lung cancer; VEGF-A, vascular endothelial growth factor A.

plotted according to the Kaplan-Meier method and determined by the log-rank test. Univariate and multivariate regression analyses were performed with the Cox proportional hazards regression model to analyze the independent factors related to prognosis. $\mathrm{P}<0.05$ was considered to indicate a statistically significant difference.

\section{Results}

Association between survivin expression and clinicopathological parameters in NSCLC. The correlation between survivin expression and clinicopathological factors of NSCLC 

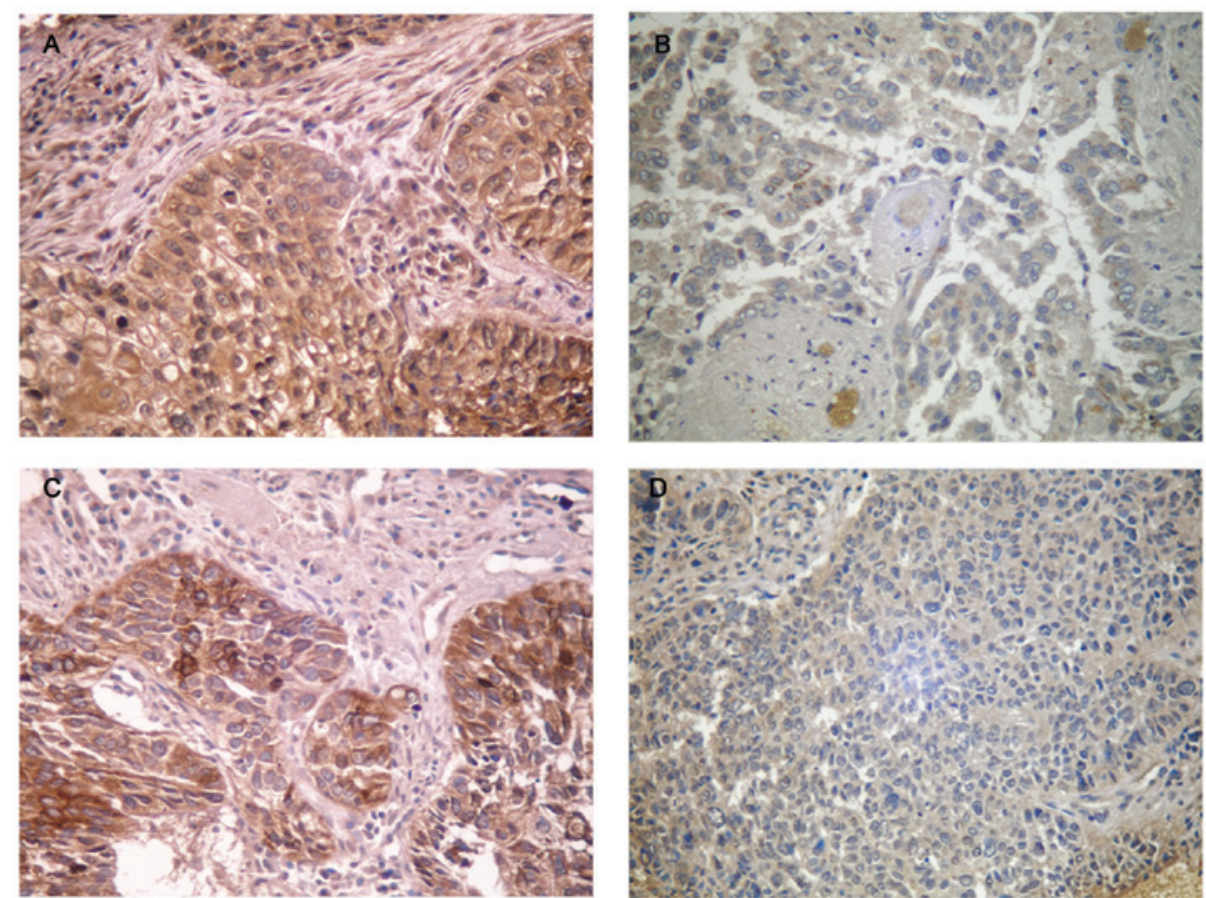

Figure 1. Immunohistochemical expression of survivin and VEGF-A protein in NSCLC tissues (SP method; magnification, x200). (A) Immunoreactivity was observed in the malignant cell cytoplasm. The brown granules in the cytoplasm indicate survivin protein in NSCLC cells. (B) Negative expression of survivin protein in NSCLC tissues. (C) Immunoreactivity was observed in the malignant cell cytoplasm. The brown granules in the cytoplasm indicate VEGF-A expression in NSCLC cells. (D) Negative expression of VEGF-A protein in NSCLC tissues. NSCLC, non-small cell lung cancer; VEGF-A, vascular endothelial growth factor A.

A

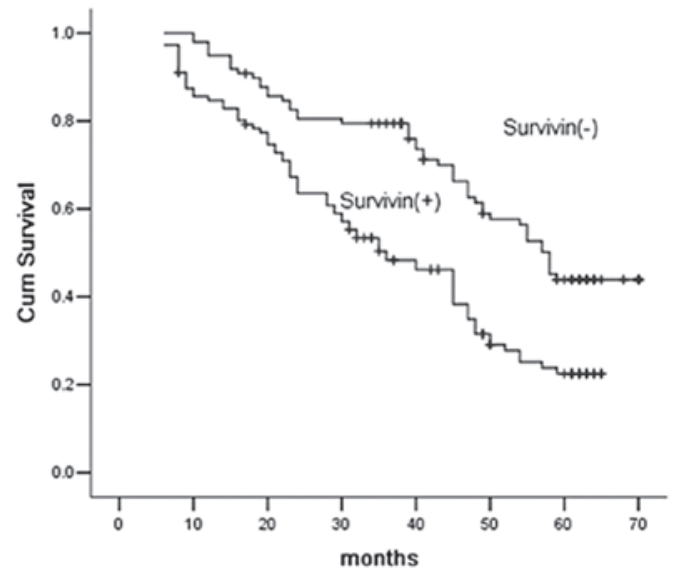

B

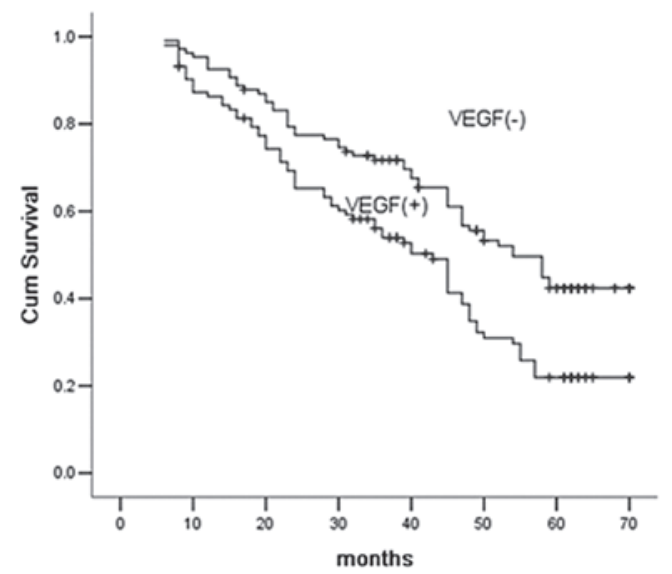

Figure 2. Overall survival curves for patients with stage III NSCLC according to the expression scores of survivin and VEGF-A. (A) The 5-year survival rates of patients with survivin-positive cancer were significantly lower compared with survivin-negative cancer patients $(\mathrm{P}<0.05)$. (B) The 5-year survival rates of patients with VEGF-A positive cancers were significantly lower compared with VEGF-A negative cancer patients $(\mathrm{P}<0.05)$. NSCLC, non-small cell lung cancer. VEGF-A, vascular endothelial growth factor A.

are shown in Table I. The expression of survivin was significantly associated with the tumor size $(\mathrm{P}=0.015)$, but had no significant correlation with age, gender, lymph node metastasis, smoking, histological type or pathological stage.

Expression of survivin and VEGF-A in NSCLC. The staining of survivin and VEGF-A was mainly localized in the cytoplasm (Fig. 1). Among the 210 stage III NSCLC cases, positive expression of survivin was observed in $112(53.3 \%)$, while negative expression was observed in $98(46.7 \%)$ cases. Survivin protein was detected in only $4(10.5 \%)$ of 38 benign tissues. Using IHC staining for VEGF-A, 103 (49.0\%) cases were positive. Out of the 112 cases of NSCLC which expressed survivin, the expression of VEGF-A was positive in 67 cases. Of the 98 cases that did not express survivin protein, 62 cases of NSCLC also did not express VEGF-A. The expression of survivin was coincident with the expression of VEGF-A in $\operatorname{NSCLC}(\mathrm{P}=0.001)$ (Table II).

Association between expression of survivin and prognosis of stage III NSCLC patients. The 5-year survival rate of the 210 patients with clinical stage III was $23.8 \%$. The survival 
Table III. Univariate analyses of prognostic factors for survival of stage III NSCLC patients.

\begin{tabular}{|c|c|c|c|}
\hline Variables & No. of cases $(n=210)$ & 5-year survival rate $(\%)$ & P-value \\
\hline \multicolumn{4}{|l|}{ Age (years) } \\
\hline$\leq 60$ & 89 & $25(28.1)$ & \multirow[t]{2}{*}{0.212} \\
\hline$>60$ & 121 & $22(20.7)$ & \\
\hline \multicolumn{4}{|l|}{ Gender } \\
\hline Male & 130 & $28(21.5)$ & \multirow[t]{2}{*}{0.325} \\
\hline Female & 80 & $22(27.5)$ & \\
\hline \multicolumn{4}{|l|}{ Tumor size $(\mathrm{cm})$} \\
\hline$\leq 3$ & 97 & $33(34.0)$ & \multirow[t]{2}{*}{0.001} \\
\hline$>3$ & 113 & $17(15.0)$ & \\
\hline \multicolumn{4}{|l|}{ Smoker } \\
\hline Yes & 105 & $24(22.9)$ & \multirow[t]{2}{*}{0.746} \\
\hline No & 105 & $26(24.8)$ & \\
\hline \multicolumn{4}{|l|}{ Lymph node metastasis } \\
\hline Yes & 108 & $35(32.4)$ & \multirow[t]{2}{*}{0.003} \\
\hline No & 102 & $15(14.7)$ & \\
\hline \multicolumn{4}{|l|}{ Pathological stage } \\
\hline G1 & 43 & $16(37.2)$ & \multirow[t]{3}{*}{0.059} \\
\hline $\mathrm{G} 2$ & 91 & $17(18.7)$ & \\
\hline G3 & 76 & $17(22.4)$ & \\
\hline \multicolumn{4}{|l|}{ Histology } \\
\hline Adenocarcinoma & 101 & $25(24.8)$ & \multirow[t]{3}{*}{0.759} \\
\hline Squamous cell carcinoma & 88 & $19(21.6)$ & \\
\hline Large-cell carcinoma & 21 & $6(28.6)$ & \\
\hline \multicolumn{4}{|l|}{ Survivin expression } \\
\hline Negative & 98 & $33(31.8)$ & \multirow[t]{2}{*}{0.002} \\
\hline Positive & 112 & $17(15.2)$ & \\
\hline \multicolumn{4}{|l|}{ VEGF expression } \\
\hline Negative & 107 & $34(31.8)$ & \multirow[t]{2}{*}{0.006} \\
\hline Positive & 103 & $16(15.5)$ & \\
\hline
\end{tabular}

NSCLC, non-small cell lung cancer; VEGF, vascular endothelial growth factor.

rate of patients with survivin-positive cancer was significantly lower than patients with survivin-negative cancer (15.2 vs. $33.7 \%$, respectively; $\mathrm{P}=0.002$ ) (Fig. 2A). In addition, VEGF-A positive cancer was associated with poor prognosis (Fig. 2B). The univariate analysis demonstrated that survivin, tumor size, lymph node metastasis and VEGF-A expression were significantly correlated with survival time (Table III). Multivariate analysis with logistic regression was performed on factors related to prognosis, and the expression of survivin, VEGF-A and lymph node metastasis were identified as independent predictive factors of poor prognosis (Table IV).

\section{Discussion}

Along with the development of more aggressive surgery and new antineoplastic agents, efforts have been made to identify patients who have a high risk of poor prognosis, as patients with the same stage NSCLC can have different risks of recurrence and survival.
Survivin is a recently discovered IAP, which is undetectable in the majority of normal adult tissues, but is overexpressed in a variety of human neoplasms, including colorectal, uterine, esophageal, bladder and liver cancer. This suggests that reactivation of the survivin gene frequently occurs in cancer (3). Survivin is a protein that is cell cycle-regulated with a robust increase in the G2/M phase in cancer cells $(12,13)$. Survivin is known to be overexpressed and related with more aggressive behavior, increased tumor recurrence, chemotherapy resistance and increased survival in various tumors $(6,14-21)$. As a prognostic factor, survivin expression is significantly associated with a poor clinical outcome in certain types of cancer, including liver (2), colorectal and breast $(3,6)$. In this large case study, it was identified that expression of the survivin protein in NSCLC tissues was positively correlated with tumor size, suggesting that survivin is significant in NSCLC evolution. Our results demonstrated that in stage III NSCLC patients, the 5-year survival rate of the NSCLC patients with survivin overexpression was significantly lower than that of NSCLC 
Table IV. Clinicopathological independent prognostic factors for survival of stage III NSCLC patients (multivariate Cox regression analyses).

\begin{tabular}{lll}
\hline Variables & $\begin{array}{c}\text { Hazard ratio } \\
(95 \% \mathrm{CI})\end{array}$ & P-value \\
\hline
\end{tabular}

Lymph node metastasis

No vs. yes

$1.906(1.334-2.723)$

$<0.001$

Survivin expression

Negative vs. positive

$1.954(1.345-2.839)$

$<0.001$

VEGF expression

Negative vs. positive

$1.461(1.015-2.104)$

0.041

NSCLC, non-small cell lung cancer; CI, confidence interval; VEGF, vascular endothelial growth factor.

patients with survivin low-expression; this was significantly associated with poor survival. In addition, survivin expression was the independent prognostic factor for stage III NSCLC cancer. Our results demonstrated that detection of survivin protein expression in the tumor tissue could predict the prognosis of stage III NSCLC patients.

Tumor growth and development is a complex multistep process, while angiogenesis is anessential step for tumor growth, playing a critical role in tumor invasion and metastasis (22). Vascular endothelial growth factor (VEGF) is considered to be the main growth-stimulating factor in tumor-related angiogenesis. In esophageal, pancreatic and colorectal cancer, VEGF overexpression was significantly correlated with poor patient prognosis, in accordance with other malignancies $(23,24)$. In malignant pleural mesothelioma, the serum level of VEGF has been reported to be significantly correlated with poor survival of patients (25). Our study revealed that in patients with stage III NSCLC, overexpression of VEGF-A in NSCLC tumor tissue was significantly correlated with a decreased 5 -year survival rate. The 5-year survival rate in patients with VEGF-A overexpression was significantly worse than that of patients with VEGF-A low-expression. These results indicate that VEGF-A may be signficant in local recurrence and metastasis through the induction of angiogenesis in NSCLC. VEGF-A expression could be a valuable marker for prognosis prediction in stage III NSCLC.

Moreover, we found that overexpression of survivin was significantly positively correlated with overexpression of VEGF-A in stage III NSCLC. To date, survivin expression appears to be regulated by growth factors, cytokines, hormones, anticancer agents and kinase inhibitors. The anti-apoptotic properties of VEGF-A and IL-11 appear to mediate the induction of survivin in endothelial cells (13). It has been revealed that VEGF-A is markedly associated with the expression of survivin in hepatocellular cancer (26), thyroid carcinoma (27) and breast cancer (28). Recently, it has been considered that the induction of survivin expression by VEGF-A employs a PI3K/Akt pathway in neuroblastoma cells (29). Consistent with these findings, we found a significantly positive correlation between survivin and VEGF-A expression in NSCLC.
Results from our multivariate analysis indicated that survivin and VEGF-A expression in NSCLC tissues were strong independent factors of poor prognosis (Table IV). These results indicated that co-analysis of VEGF-A and survivin protein expression were valuable for prognosis evaluation of an NSCLC patient.

Since the role and prognostic significance of survivin in various types of cancer were discovered, different types of survivin molecular antagonists have been studied (30). Further investigation, however, concerning this is required. In conclusion, our study demonstrates that survivin expression is associated with tumor size in stage III NSCLC. The expression of survivin is consistent with expression of VEGF-A in NSCLC; it was correlated with a poor prognosis of stage III NSCLC. Increased systemic treatments or targeted antagonists of survivin and VEGF-A are required for cases overexpressing survivin and VEGF-A.

\section{References}

1. Jemal A, Siegel R, Ward E, Hao Y, Xu J and Thun MJ: Cancer statistics. CA Cancer J Clin 59: 225-249, 2009.

2. Srinivasula SM and Ashwell JD: IAPs: what's in a name? Mol Cell 30: 123-135, 2008.

3. Hernandez JM, Farma JM, Coppola D, Hakam A, Fulp WJ, Chen DT, Siegel EM, Yeatman TJ and Shibata D: Expression of the antiapoptotic protein survivin in colon cancer. Clin Colorectal Cancer 10: 188-193, 2011.

4. Pavlyukov MS, Antipova NV, Balashova MV, Vinogradova TV, Kopantzev EP and Shakhparonov MI: Survivin monomer plays an essential role in apoptosis regulation. J Biol Chem 286: 23296-23307, 2011.

5. Nowak-Markwitz E, Puła B, Szajnik M, Dziegiel P, Piotrowska A, Zabel M and Spaczyński M: Expression of survivin, SDF-1 and CXCR on tumor cells in ovarian cancer. Ginekol Pol 81: 674-677, 2010.

6. Kim K, Chie EK, Wu HG, Kim SG, Lee SH, Kang GH, Hyun CL and Ha SW: High survivin expression as a predictor of poor response to preoperative chemoradiotherapy in locally advanced rectal cancer. Int J Colorectal Dis 26: 1019-1023, 2011.

7. Adamkov M, Halasova E, Kajo K, Machalekova K, Vybohova D, Varga I and Rajcany J: Survivin: a promising biomarker in breast carcinoma. Neoplasma 57: 572-577, 2010.

8. Hoffman WH, Biade S, Zilfou JT, Chen J and Murphy M: Transcriptional repression of the anti-apoptotic survivin gene by wild type p53. J Biol Chem 277: 3247-3257, 2002.

9. Mirza A, McGuirk M, Hockenberry TN, Wu Q, Ashar H, Black S, Wen SF, Wang L, Kirschmeier P, Bishop WR, Nielsen LL, Pickett $\mathrm{CB}$ and Liu $\mathrm{S}$ : Human survivin is negatively regulated by wild-type p53 and participates in p53-dependent apoptotic pathway. Oncogene 21: 2613-2622, 2002.

10. Lee CW, Raskett CM, Prudovsky I and Altieri DC: Molecular dependence of estrogen receptor-negative breast cancer on a notch-survivin signaling axis. Cancer Res 68: 5273-5281, 2008.

11. Vaira V, Lee CW, Goel HL, Bosari S, Languino LR and Altieri DC: Regulation of survivin expression by IGF-1/mTOR signaling. Oncogene 26: 2678-2684, 2007.

12. Li F: Survivin study: what is the next wave? J Cell Physiol 197: 8-29, 2003.

13. Altieri DC, Marchisio PC and Marchisio C: Survivin apoptosis: an interloper between cell death and cell proliferation in cancer. Lab Invest 79: 1327-1333, 1999.

14. Shu MG, Guo XT, Zhen HN, Han Y, Chen FL, Li LW and Guo SZ: Enhancing skin flap survival by a cell-permeable wild-type survivin. Med Hypotheses 69: 888-891, 2007.

15. Zhu H, Wang Q, Hu C, Zhang W, Quan L, Liu M, Xu N and Xiao Z: High expression of survivin predicts poor prognosis in esophageal squamous cell carcinoma following radiotherapy. Tumour Biol 32: 1147-1153, 2011.

16. Trabulo S, Cardoso AM, Santos-Ferreira T, Cardoso AL, Simões S and Pedroso de Lima MC: Survivin silencing as a promising strategy to enhance the sensitivity of cancer cells to chemotherapeutic agents. Mol Pharm 8: 1120-1131, 2011. 
17. Park E, Gang EJ, Hsieh YT, Schaefer P, Chae S, Klemm L, Huantes S, Loh M, Conway EM, Kang ES, Hoe Koo H, Hofmann WK, Heisterkamp N, Pelus L, Keerthivasan G, Crispino J, Kahn M, Müschen M and Kim YM: Targeting survivin overcomes drug resistance in acute lymphoblastic leukemia. Blood 118: 2191-2199, 2011.

18. Takizawa BT, Uchio EM, Cohen JJ, Wheeler MA and Weiss RM: Downregulation of survivin is associated with reductions in TNF receptors' mRNA and protein and alterations in nuclear factor kappa B signaling in urothelial cancer cells. Cancer Invest 25: 678-684, 2007

19. Ai Z, Yin L, Zhou X, Zhu Y, Zhu D, Yu Y and Feng Y: Inhibition of survivin reduces cell proliferation and induces apoptosis in human endometrial cancer. Cancer 107: 746-756, 2006.

20. Malcles MH, Wang HW, Koumi A, Tsai YH, Yu M, Godfrey A and Boshoff C: Characterisation of the anti-apoptotic function of survivin-DeltaEx3 during TNF alpha-mediated cell death. Br J Cancer 96: 1659-1666, 2007.

21. Nassar A, Lawson D, Cotsonis G and Cohen C: Survivin and caspase-3 expression in breast cancer: correlation with prognostic parameters, proliferation, angiogenesis, and outcome. Appl Immunohistochem Mol Morphol 16: 113-120, 2008.

22. Ferrara N, Gerber HP and LeCouter J: The biology of VEGF and its receptors. Nat Med 9: 669-676, 2003.

23. Giatromanolaki A, Sivridis E and Koukourakis MI: Angiogenesis in colorectal cancer: prognostic and therapeutic implications. Am J Clin Oncol 29: 408-417, 2006.

24. Kleespies A: Vascular endothelial growth factor in esophageal cancer. J Surg Oncol 87: 95-104, 2004.
25. Yasumitsu A, Tabata C, Tabata R and Hirayama N: Clinical significance of serum vascular endothelial growth factor in malignant pleural mesothelioma. J Thorac Oncol 5: 479-483, 2010.

26. Zhu H, Chen XP, Zhang WG, Luo SF and Zhang BX: Expression and significance of new inhibitor of apoptosis protein survivin in hepatocellular carcinoma. World J Gastroenterol 11: 3855-3859, 2005.

27. Zhang HY, Meng X, Du ZX, et al: Significance of survivin, caspase-3, and VEGF expression in thyroid carcinoma. Clin Exp Med 9: 207-213, 2009.

28. Ryan BM, Konecny GE, Kahlert S, Wang HJ, Untch M, Meng G, Pegram MD, Podratz KC, Crown J, Slamon DJ and Duffy MJ: Survivin expression in breast cancer predicts clinical outcome and is associated with HER2, VEGF, urokinase plasminogen activator and PAI-1. Ann Oncol 17: 597-604, 2006.

29. Beierle EA, Nagaram A, Dai W, Iyengar $M$ and Chen MK: VEGF-mediated survivin expression in neuroblastoma cells. J Surg Res 127: 21-28, 2005.

30. Nakahara T, Yamanaka K, Hatakeyama S, Kita A, Takeuchi M, Kinoyama I, Matsuhisa A, Nakano K, Shishido T, Koutoku H and Sasamata M: YM155, a novel survivin suppressant, enhances taxane-induced apoptosis and tumor regression in a human Calu 6 lung cancer xenograft model. Anticancer Drugs 22: 454-462, 2011 